DOI: $10.14451 / 1.193 .352$

\title{
КОНЦЕПЦИЯ ПРИВЛЕЧЕНИЯ ПРЯМЫХ ИНВЕСТИЦИЙ В РЕГИОНЫ РОССИИ
}

\author{
(c) 2020 Огнивцев Сергей Борисович \\ доктор экономических наук, профессор
}

заместитель директора ОКУ «Агентство по инновациям и развитию социальных и экономических проектов», директор Института системного анализа и интеллектуальной собственности

В статье проведен анализ современного состояния инвестиционной сферы России, включая инструменты развития территорий и инвестиционных проектов. Рассмотрены различные типы территорий с особыми режимами предпринимательской деятельности и преференциальные инвестиционные проекты. Проанализирован международный опыт привлечения инвестиций и работы зарубежных агентств продвижения инвестиций. Сформулированы цели и задачи инвестиционного развития и проблемы, препятствующие достижению этих целей. Предложены основные направления привлечения инвестиций, включая стратегическое управление инвестиционными потоками, стратегическую специализацию различных типов особых территорий, снижение риска девальвации рубля для инвесторов, вкладывающих в проект средства в иностранной валюте, и организацию Агентства привлечения и продвижения инвестиций (АППИ) и Центра привлечения инвесторов (ЦПИ). Приведены основные функции АППИ и ЦПИ.

Ключевые слова: национальные цели, национальные проекты, инвестиции, особые экономические зоны, территории опережающего развития, инновационные научно-технологические центры, индустриальные парки, хеджирование валютных рисков.

\section{1. Современное состояние инвестици-} онной сферы.

Инвестиции в основной капитал в Российской Федерации составили в 2019 году 19,3 трлн. руб. или около $17 \%$ ВВП [1]. Это довольно низкий и тревожный показатель. Как правило, доля инвестиций в ВВП стран с ростом ВВП около $3 \%$ составляет, как минимум, $21 \%$, а устойчивы рост экономики начинается с ростом доли инвестиций до 25\%. Ситуация в 2020 году еще более ухудшилась в связи с пандемией covid-19. По прогнозам экспертов, инвестиции в 2020 году упадут примерно на 7,7\%.

По данным экспертов ЮНКТАД [2], в 2019 году прямые иностранные инвестиций (ПИИ) в мире составили 1,39 млрд. долл. При этом ПИИ в Россию находятся на уровне около 32 млрд. долл. или $2,3 \%$ от ПИИ в мире и $11,6 \%$ от всех инвестиций в основной капитал. ПИИ шли в сектор добычи полезных ископаемых $-61,5 \%$, в обрабатывающую промышленность - 24,6\% и финансовый сектор - 20,8\%.

При этом ПИИ в 2019 году в Соединенные Штаты составили 251 млрд. долл., в Китай - 140 млрд. долл., в ЕС в сумме - 305 млрд. долл. и в маленький Сингапур - 110 млрд. долл.

Такое положение дел не может нас устраивать. Указы Президента России «О националь- ных целях и стратегических задачах развития Российской Федерации на период до 2024 года» от 7 мая 2018 года и «О национальных целях развития Российской Федерации на период до 2030 года» от 21 июля 2020 года ставят в инвестиционной сфере целый ряд амбициозных задач. Центральное место занимает национальная цель обеспечить «реальный рост инвестиций в основной капитал не менее 70 процентов по сравнению с показателем 2020 года». Это позволит России выйти на уровень инвестиций более $25 \%$ ВВП, что обеспечивает достаточную скорость роста экономики.

Для роста инвестиций в основной капитал используются довольно разнообразные инструменты.

2. Инструменты развития территорий и инвестиционных проектов.

Применяемые инструменты и институты привлечения инвестиций можно разделить на две группы: территории с особым режимом предпринимательской деятельности (особые территории) и инвестиционные проекты с преференциальными налоговыми режимами и мерами государственной поддержки (особые инвестиционные проекты).

$\mathrm{K}$ настоящему времени создано и развиваются несколько типов особых территорий. 
1) Особые экономические зоны (ОЭЗ) создаются в соответствии с Федеральным законом от 22.07.2005 № 116-ФЗ «Об особых экономических зонах в Российской Федерации». Законом определеныпромышленные,технико-внедренческие, туристическо-рекреационные и портовые ОЭЗ. В силу закона ОЭЗ создаются «в целях развития обрабатывающих отраслей экономики, высокотехнологичных отраслей экономики, развития туризма, санаторно-курортной сферы, портовой и транспортной инфраструктур, разработки технологий и коммерциализации их результатов, производства новых видов продукции». В настоящее время функционирует 33 ОЭЗ (15 ОЭЗ промышленно-производственного типа, 7 технико-внедренческого типа, 10 - туристскорекреационного типа и одна портовая ОЭЗ). Общий объем заявленных инвестиций резидентов за 2005-2019 гг. составляет 1218,3 млрд. рублей, из которых уже осуществлено 447,6 млрд. рублей (36,7\%). Резидентами ОЭЗ создано 42,1 тыс. рабочих мест. Объем выручки от продажи товаров, выполнения работ, оказания услуг составил 968,5 млрд. рублей [3]. По особым правилам созданы и функционируют особые экономические зоны в Калининградской и Магаданской областях и Свободная экономическая зона на территориях Республики Крым и города федерального значения Севастополя. Как остаточное явление остались ОЭЗ регионального уровня (они начали создаваться до федерального закона и кое-где остались; это сейчас незаконно).

2) Территории опережающего развития (ТОР) создаются в соответствии с Федеральным законом от 29.12.2014 № 473-ФЗ «О территориях опережающего социально-экономического развития в Российской Федерации». Территории опережающего социально-экономического развития (ТОСЭР) создаются с 1 января 2018 г. на Дальнем Востоке и в Арктике. Сюда входит Свободный порт Владивосток. ТОР создаются в монопрофильных муниципальных образованиях (моногородах) и в закрытых административных территориальных образованиях (ЗАТО). Цель - ускоренное социально-экономического развитие и создания комфортных условий для обеспечения жизнедеятельности населения. К настоящему времени на Дальнем Востоке создано 21 ТОР, вложения в которые федерального бюджета составили 21 млрд. рублей, инвестиции резидентов - 711 млрд. рублей (четверть от заявленной суммы); создано 25 тыс. рабочих мест.
В моногородах - 87 ТОР. В них создано более 27 тыс. рабочих мест, привлечено на ноябрь 202075 млрд. рублей. Выручка резидентов составила более 149 млрд. рублей [4].

3) Инновационные научно-технологические центры (ИНТЦ) создаются в соответствии с Федеральным законом «Об инновационных научно-технологических центрах» № 216-ФЗ от 29.07.2017. Цель ИНТЦ - осуществление научнотехнологической деятельности, включающую научно-техническую и инновационную деятельность, выполнение исследований и разработок, реализация научно-технических проектов, использование полученных научных и (или) научно-технических результатов, результатов интеллектуальной деятельности, в том числе их коммерциализация, по направлениям, определенным в решении о создании инновационного научно-технологического центра. Создано 6 и имеются заявки еще на 5-7 ИНТЦ.

4) Зоны территориального развития (ЗТР) создаются в соответствии с Федеральным законом «О зонах территориального развития в Российской Федерации» от 03.12.2011 № 392-Ф3. Цель - развитие слабых муниципальных образований в экономически отстающих регионах. Каждые три года Правительство РФ определяет регионы, в которых можно образовывать ЗТР. Последнее постановление в 2019 году определило 20 таких регионов.

5) Индустриальные парки (ИП) создаются в соответствии с Федеральным законом «О промышленной политике в Российской Федерации» от 31.12.2014 № 488-Ф3 для «создания промышленного производства или модернизации промышленного производства». К настоящему времени создано и создается 269 ИП. Их общая площадь - примерно 55 тысяч га. В 2019 году 2507 резидентов начало производство в ИП. Создано 192,61 тысячи рабочих мест. Государственные инвестиции в инфраструктуру индустриальных парков составляют 244 млрд. руб., а инвестиции резидентов - 1,254 трлн. рублей. При этом 90\% инвестиций приходится на 16 регионов, а 2/3 - на Калужскую, Липецкую, Московскую области и Республику Татарстан [5].

6) Промышленные технопарки (ПТ), создаваемые в соответствии с Федеральным законом «О промышленной политике в Российской Федерации» от 31.12.2014 № 488-ФЗ. целях освоения производства промышленной продукции и коммерциализации полученных научно- 
технических результатов. На 2020 год создано 294 промышленных технопарков в 66 регионах РФ.

ОЭЗ, ТОР, ЗТР и ИНТЦ подведомственны Минэкономразвития РФ, за исключением ТОР, создаваемых на Дальнем Востоке и в Арктике. Эти ТОР подведомственны министерству по развитию Дальнего Востока и Арктики. ОЭЗ, ТОР и ИНТЦ работают по государственной программе РФ «Экономическое развитие и инновационная экономика».

ИП и ПТ подведомственны Минпромторгу РФ и работают по Государственной программе РФ «Развитие промышленности и повышение ее конкурентоспособности».

К особым инвестиционным проектам мы относим все крупные инвестиционные проекты, проходящие с государственным (или муниципальным) участием и бюджетной поддержкой. Среди них: специальные федеральные и региональные инвестиционные проекты, определенные статьей 16 Федерального закона от 31.12.2014 № 488-Ф3 «О промышленной политике в Российской Федерации» (СПИК), а также особо значимые или важные инвестиционные проекты, определенные региональными законами, и др. Минимальные размеры поддерживаемых государством инвестиционных проектов определены федеральным и региональным законодательством.

Существенный вклад в привлечение инвестиций в особые инвестиционные проекты должен внести Федеральный закон от 1 апреля 2020 г. № 69-Ф3 «О защите и поощрении капиталовложений в Российской Федерации», который, в частности, гарантирует инвесторам стабильность условий инвестирования.

\section{3. Зарубежный опыт.}

В большинстве зарубежных стран существуют Агентства по привлечению инвестиций (АПИ). Всемирная ассоциация инвестиционных агентств (World Association of Investment Promotion Agencies - WAIPA) объединяет 173 организации из 130 стран.

Большая часть АПИ (60\%) - автономные агентства. Около 31\% всех АПИ - государственные организации, 6\% - государственно-частное и только одно - частное. В среднем, государственное финансирован е составляет 98\% бюджета АПИ. Средний бюджет одного АПИ стран ОЭСР составляет 68 млн. долл. в год [6].

Анализ деятельности АПИ позволяет выде- лить четыре ключевые функции [7].

Основная ключевая функция АПИ - создание новых инвестиционных проектов или генерация инвестиций. На это направление тратится около 40\% бюджета. АПИ входит в непосредственный контакт с потенциальным инвестором и убеждает его инвестировать в представляемую им страну.

Другой ключевой функцией большинства АПИ является облегчение процедур инвестирования и обслуживания уже имеющихся инвесторов с целью их удержания и расширения их сферы деятельности в стране пребывания (30\% бюджета). АПИ работает над облегчением внедрения проектов инвестора и максимизацией получаемых им доходов от внедряемых проектов. Обслуживание инвестора идет на протяжении всего цикла инвестирования.

Около 18\% бюджета среднего АПИ тратится на создание имиджа страны и ее регионов. Для этого различными способами распространяется информация об инвестиционной привлекательности страны.

На пропаганду государственной инвестиционной политики в среднем расходуется около 6\% бюджета АПИ. В рамках этого направления проводится мониторинг инвестиционного климата и его восприятия инвесторами.

Многие АПИ в качестве прототипа выбрали Управление по торговле и инвестициям Великобритании (UKTI), которое с 2016 года стало Департаментом международной торговли. Департамент сопровождает более 1700 проектов из 2213 зарегистрированных инвестиционных проектов, то есть 80\% всех проектов Великобритании, в результате которых было создано 82,6 тысяч рабочих мест.

Аналогичные государственные агентства работают в США, Kuтае, ФРГ, Сингапуре, Бразилии, Франции, Нидерландах, Австралии, Индии и в других странах.

\section{ций.}

4. Проблемы в привлечении инвести-

Привлечению инвестиций и развитию инвестиционных процессов в регионах России препятствуют следующие проблемы.

1) Привлечение инвестиций в регионы России происходит на основе взаимодействия инвесторов и властей регионов без достаточного учета Стратегии социально-экономического развития России, Стратегий развития отдельных отраслей экономики и Стратегии простран- 
ственного развития России.

2) Несмотря на разнообразие особых территорий, большинство из них работают без строгой ориентации на цели конкретного типа особой территории, как обычные промышленные зоны, которые принимают практически любого инвестора, независимо от направления его инвестиционного проекта. В соответствии с поручением Президента России № Пр-1028 от 27.05.2016 года Правительству РФ необходимо разработать Единую стратегию создания и функциионирования инструментов развития территорий, включая особые экономические зоны (ОЭЗ), территории опережающего развития (ТОР), индустриальные парки (ИП), промышленные технопарки (ПП) в сфере высоких технологий, инновационные научно-технологические центры (ИНФЦ), и др. Однако до сих пор поручение не выполнено, а свою актуальность оно, отнюдь, не потеряло.

3) Для привлечения иностранных инвесторов важную роль играет не только неизменность институтов на время осуществления инвестиционных проектов, что, в определенной мере, гарантируется законом «О защите и поощрении капиталовложений в Российской Федерации», но и стабильностью курса рубля. Быстрая девальвация рубля, идущая скачками последние пятьшесть лет, делает невыгодным осуществление в России экономически эффективные в рублях долгосрочных инвестиционных проектов с вложениями в долларах, евро и других ведущих валютах.

4) В России отсутствует единое агентство привлечения и продвижения инвестиций, работающее по принципу «одного окна». Регионы конкурируют за привлечение инвесторов, предлагая им наиболее выгодные условия. Эта конкуренция, конечно, выгодна инвесторам, но часто совсем не выгодна регионам и России, в целом. Региональные власти и агентства по привлечению инвестиций не имеют возможности собрать и проанализировать достаточно полную и всеобъемлющую информацию об иностранных компаниях, которые было бы целесообразно привлечь как инвесторов. Часто у них нет квалифицированных кадров для формирования и экспертизы инвестиционных проектов. Нет опыта ведения переговоров. Выход на инвестора обычно носит случайный, а не системный характер, например, на выставках. Поэтому рынок ПИИ в России остается рынком инвесторов, а регионы оста- ются в положении пассивных участников. Выбор остается только за инвесторами.

5. Цели и задачи привлечения инвестиций.

Основной цзелью привлечения инвестиций является выполнение национальной цели - обеспечить к 2030 году «реальный рост инвестиций в основной капитал не менее 70 процентов по сравнению с показателем 2020 года». Для этого потребуется увеличить объем инвестиций не менее чем на 12,6 трлн. рублей (в ценах 2019 года). Следует отметить, что большая часть этого роста будет обеспечена действующими предприятиями в ходе естественного расширенного воспроизводства. Привлечение инвестиций дает дополнительный рост инвестиций.

Для привлечения и продвижения инвестиций необходимо решить следующие задачи.

1) Осуществить переход к стратегическому управлению инвестиционными потоками, то есть стимулировать именно те инвестиции, которые направлены на выполнение стратегических целей развития страны и регионов в соответствии со Стратегией пространственного развития.

2) Перестроить различные уже созданные и создающиеся типы особых территорий в систему, соответствующую национальным и стратегическим целям развития страны.

3) Ввести механизмы хеджирования рисков девальвации рубля для инвесторов, вкладывающим в инвестиционные проекту средства в валюте.

4) Организовать Агентство привлечения $и$ продвижения инвестиций (АППИ), которое возьмет на себя обслуживание инвесторов по принципу «одного окна» и станет центром компетенции и консалтинга для региональных агентств привлечения инвестиций.

6. Направления привлечения и продвижения инвестиций.

Основные направления привлечения и продвижения инвестиций соответствуют поставленным задачам. Прежде всего, следует отметить, что современное отношение к инвестициям и инвесторам, как к абсолютному благу, во многом, ошибочно. Действительно, для привлечения инвестиций обычно используют инструменты особых территорий и особых инвестиционных проектов. Это дает инвесторам определенные конкурентные преимущества и приводит к искажению рынка. Поэтому привлечение инвестиций в регион может привести к 
ухудшению общей экономической ситуации, и в каждом случае нужно взвешивать положительные и отрицательные последствия от прихода нового инвестора. На искусственное искажение рынка можно пойти, если оно приводит к достижению важных национальных или стратегических целей развития страны и региона.

6.1. Стратегическое управление инвестиционными потоками. В идеале цели стратегии социально-экономического развития страны должны быть декомпозированы в отраслевом разрезе в целевые показатели стратегий развития отдельных групп отраслей, например, стратегию развития обрабатывающей промышленности, стратегию развития пищевой промышленности, стратегию развития туризма и т.д. Целевые показатели каждой такой стратегии должны, в свою очередь, декомпозироваться в целевые показатели развития отдельных отраслей.

С другой стороны, параллельно должна проходить территориальная декомпозиция целевых показателей, за координацию которых отвечает Стратегия пространственного развития России. Целевые показатели социально-экономического развития регионов должны соответствовать целевым показателям развития отдельных отраслей страны.

Таким образом, в конкретном регионе должны связаться целевые показатели отраслевых и территориальных стратегий развития. То есть, например, из пространственной стратегии развития РФ, с одной стороны, и из Стратегии развития обрабатывающей промышленности следует, что в Тамбовской области должно быть организовано производство биотехнологического оборудования для глубокой переработки зерна. При этом известна примерная номенклатура и количество необходимого оборудования по годам.

Это означает, что у нас уже есть перспективный рынок сбыта, актуальность которого гарантируется стратегическим планированием территориального и отраслевого развития. Для привлечения инвестора главное - наличие рынка сбыта его продукции. Если строительство нового предприятия вписывается в стратегию развития определенной отрасли, например, биотехнологической промышленности, то можно рассчитывать, что к моменту ввода предприятия в строй будет сформирован соответствующий спрос на его продукцию.

K подготовленному рынку сбыта могут быть добавлены определенные преференции по импортным тарифам и налогам. Например, планируемое предприятие можно разместить в ОЭЗ или ТОР. Кроме того, в случае импортозамещения можно предусмотреть увеличение импортных тарифов или тарифных квот на конкурирующую зарубежную продукцию.

Теперь все вышесказанное нужно оформить в виде привлекательного, профессионально выполненного бизнес-плана работы будущего предприятия. Это может сделать региональное агентство привлечения инвестиций при методической и консультационной поддержке федерального Агентства привлечения и продвижения инвестиций (АППИ). От качества расчетов, прилагаемых документов и, главное, убедительности и доказательности определения рынка сбыта, в решающей степени, зависит успех в привлечении инвестиций.

Указанные документы, включая расчеты, в соответствии с законом «О защите и поощрении капиталовложений в Российской Федерации» размещаются администрацией региона в Интернет, как публичное предложение инвестору. Если документы сделаны грамотно и рынки сбыта продукции определены, инвесторы обязательно найдутся. Соглашение будет заключено с тем инвестором, который предложит лучшие для региона условия осуществления инвестиционного проекта.

Конечно, выше описана идеальная ситуация, когда Федеральный закон от 28.06.2014 № 172Ф3 «О стратегическом планировании в Российской Федерации» полностью и безукоризненно исполняется, все стратегические документы разработаны, а целевые показатели всех стратегий взаимоувязаны. Сейчас этого, конечно, нет. Но к этому нужно стремиться. Если в конкретном случае отраслевые стратегии не дают четких целевых ориентиров и не связаны со Стратегией пространственного развития, нужна, как почти всегда у нас, ручная настройка. Ее должно проводить Минэкономразвития России и подведомственное ему АППИ.

Возможен, естественно, и обратный процесс, который начинается по инициативе инвестора. Он хочет осуществить определенный инвестиционный проект и, следуя принципу «одного окна», приходит в АППИ. Там проводят экспертизу проекта, сопоставляют его с отраслевыми стратегиями развития и стратегиями развития отдельных территорий и на основании этого анализа предлагают инвестору один или не- 
сколько регионов и, возможно, особых территорий для размещения проекта. АППИ помогает инвестору и региону провести переговоры и заключить соглашение о внедрении инвестиционного процесса, а также защите и стимулированию инвестиций.

6.2. Стратегическая спец̧иализациия различных типов особых территорий. В настоящее время особые территории имеют законодательно определенную специализацию, но реально они, в основном, выступают в форме индустриальных парков или снабженных инфраструктурой промышленных зон, в которых может быть размещено практически любое производство. Для индустриального парка это вполне естественно - государство создает инфраструктуру промышленной зоны именно для размещения промышленного производства. Однако для ОЭЗ, ТОР и других особых территорий с существенными преференциями резидентов такой подход не верен.

Особые территории должны составлять единую взаимосвязанную систему, в которой каждый элемент (тип особой территории) будет предназначен для выполнения собственных целей, а в целом, они будут способствовать выполнению национальных целей, в частности, в сферах инновационного развития и модернизации ведущих отраслей обрабатывающей промышленности.

Первое звено в этой цепи особых территорий должны занять инновационные научнотехнологические центры (ИНФЦ), в которых генерируются новые инновационные проекты. Здесь организуется опытное производство.

В особых экономических зонах техниковнедренческого типа (ОЭЗ ТВТ) размещаются различные инновационные и модернизационные инвестиционные проекты. В этих ОЭЗ инвестиционные проекты, сгенерированные в ИНФЦ, могут внедряться в промышленное производство.

ОЭЗ промышленно-производственного типа (ОЭЗ ППТ) предназначены для освоения проектов модернизации обрабатывающей промышленности. В этих зонах должны размещаться предприятия с новейшими технологиями и, возможно, импортным оборудованием и сырьем. Эти предприятия должны быть ориентирами для развития соответствующих отраслей промышленности.

Наконец, территории опережающего развития (ТОР), индустриальные парки (ИП), про- мышленные технопарки (ПТ) и территории опережающего развития представляют собой зоны массового освоения новых моделей предприятий, прошедших апробацию в ОЭЗ.

Предлагаемая схема взаимодействия различных особых территорий ИНТЦ $\rightarrow$ ОЭЗ ТВТ $\rightarrow$ ОЭЗ ППТ $\rightarrow$ ИП, ПТ, ТОР может стать эффективным инструментом осуществления крупных национальных проектов. В качестве примера рассмотрим Национальный проект «Малое и среднее предпринимательство (МСП) и поддержка индивидуальной предпринимательской инициативы». Он ставит цели довести: 1) численность занятых в сфере малого и среднего предпринимательства, включая индивидуальных предпринимателей до 25 млн. человек к 2024 году (сейчас примерно 20 млн.); 2) долю малого и среднего предпринимательства в ВВП до 32,5\% (сейчас примерно 23\%); 3) долю экспорта субъектов малого и среднего предпринимательства в общем объеме несырьевого экспорта до 10\% (сейчас примерно 8,6\%) [9].

Важное место в осуществлении этого национального проекта отводится федеральному проекту «Акселерация субъектов малого и среднего предпринимательства», направленному на «ускоренное развитие в таких областях, как благоустройство городской среды, научнотехнологическая сфера, социальная сфера и экология».

Поскольку ставится цель создания высокотехнологичных производств, для обеспечения выполнения федерального проекта целесообразно использовать предложенную нами схему:

1) Организуется один или несколько ИНТЦ, которые генерируют и доводят до стадии опытной эксплуатации инновационные инвестиционные проекты и апробируют бизнес модели, предназначенные для их использования малым и средним бизнесом. Например, в ИНТЦ «Мичуринская долина» размещаются отечественные и зарубежные инновационные производства в сфере АПК. Каждое производство проходит в ИНТЦ опытную эксплуатацию и может быть приобретено по договору франшизы или лицензионному соглашению для создания аналогичных предприятий в регионах страны.

2) Параллельно организуются или перепрофилируются одна или несколько ОЭЗ ТВТ. В таких ОЭЗ размещаются инновационные или технологически передовые производства по различным отраслям обрабатывающей промышленности. В отличие от ИНТЦ в ОЭЗ размещаются 
предприятия с уже апробированными инновациями, прошедшие стадию опытной эксплуатации, в частности в ИНТЦ. Эти предприятия также могут масштабироваться с использованием договоров франшизы или лицензионных соглашений.

3) В ИНТЦ и ОЭЗ ТВТ работают «постоянные образовательные программы, которые обеспечивают обучение региональных (муниципальных) команд» на наглядных примерах работающих предприятий (мероприятие 5.4 федерального проекта, 1000 команд).

4) Далее в прямом соответствии с мероприятием 5.1 федерального проекта организуется «создание в субъектах Российской Федерации не менее 129 промышленных парков, технопарков, в том числе в сфере высоких технологий и агропромышленного производства...». Подготовленные к внедрению в ИНТЦ и ОЭЗ ТВТ производства передаются в указанные индустриальные, промышленные парки, в которых проводится «расиирение использования франшиз в секторе МСП» (не менее 20 новых франшиз в регионах ежегодно по мероприятию 5.7 федерального проекта).

Отдельно следует рассматривать привлечение резидентов, производство которых ориентировано на экспорт. Если инвестор хочет создать производство, встроенное в международные цепочки добавленной стоимости, и намеревается производить продукцию, главным образом из импортного сырья или импортных комплектующих для экспорта своей продукции, его нужно всячески поощрять и стимулировать. Его производство не будет оказывать негативного влияния на внутренний рынок, но создаст дополнительные рабочие места. Поэтому экспортно-ориентированные производства в первую очередь должны размещаться в особых территориях. Особенно эффективно размещение таких предприятий в портовых ОЭЗ.

Привлечение инвестиций в особые территории, расположенные в депрессивных регионах (зоны территориального развития, ОЭ3), требуют дополнительных стимулов для инвесторов. Например, можно предложить дополнить предусмотренные Федеральным законом «О зонах территориального развития в Российской Федерации» меры льготами по налогу на доходы физических лиц. Например, можно предусмотреть снижение этого налога при выплате дивидендов.

6.3. Снижение риска девальвации рубля для инвесторов, вкладывающих в проект средства в иностранной валюте. Не секрет, что большая часть средств потенциальных российских инвесторов хранится в валюте. За последние годы перевод рублевых средств в валюту доказал свою высокую эффективность по сравнению с вложениями рублей в инвестиционные проекты. Российские и, тем более, иностранные инвесторы опасаются вкладывать имеющиеся валютные средства в российские инвестиционные проекты, поскольку велики риски получения убытка в валюте из-за потенциальной девальвации рубля.

Конечно, существует немало биржевых и небиржевых инструментов хеджирования валютных рисков: форвардные контракты, сделки РЕПО, валютные опционы и фьючерсы и т.д. Однако хеджировать валютные риски на полный цикл инвестирования до полного возврата инвестиционных вложений и получения прибыли, довольно сложно технически и дорого.

В связи с этим предлагается предусмотреть государственные меры нивелирования или уменьшения валютного риска для инвесторов, по крайней мере, в части возврата инвестиционных вложений. Для этого инвестор заключает с уполномоченной организацией (далее УО, это может быть АППИ, фонд или банк) соглашение, в котором декларируется график инвестиций (суммы в валюте и моменты вложений), срок окончания проекта и график возврата инвестиций. В уполномоченной организации для этого инвестора вносится запись в специальный реестр, в котором фиксируются инвестиционные вложения с датой и валютным курсом на эту дату.

Для обеспечения инвестора средствами в рублях УО получает из бюджета беспроцентный или низкопроцентный заем, соответствующий поступлению валютных средств по курсу на момент поступления. Валютные средства оформляются как залог получения займа. УО заключает симметричный договор займа с инвестором и направляет ему заемные средства. Используя их, инвестор реализует свой проект, например, строит предприятие в ОЭЗ. После запуска предприятия он направляет свою прибыль на покрытие займа. По мере погашения займа внесенные инвестором валютные средства освобождаются от залоговых обязательств и возвращаются инвестору по курсу, который был на момент внесения. УО может использовать внесенные на его счет инвесторами валютные средства, вкладывая их в строго законодательно или нормативно ограниченные практически безрисковые виды валютных активов, например, трежерис или еврооблигации крупнейших ТНК. Часть доходов от 
этих вложений может передаваться в бюджет, а оставшаяся часть использоваться для обеспечения работы УО.

Эта мера, без сомнения, приведет к значительному росту инвестиций и будет приносить доход бюджету на длительном интервале времени. Дополнительные инвестиции приведут к появлению новых предприятий, выручка которых, в среднем, будет примерно равна суммарным привлеченным инвестициям, а налоги в бюджеты всех уровней (включая НДС и страховые выплаты) составляют не менее $20 \%$, даже с учетом разнообразных преференций.

Можно предложить и другие способы нивелирования или уменьшения валютных рисков при инвестировании. Например, УО может управлять рисками инвесторов через приобретенные ими опционы. После каждого вложения инвестор приобретает опцион на покупку валюты по курсу на момент внесения. Уполномоченная организация получает приобретенные инвесторами опционы в доверительное управление и за счет профессионализма своих сотрудников и использования оптовых скидок существенно уменьшает расходы по долгосрочному управлению опционным портфелем. Государство из бюджетных средств может покрывать часть расходов УО и, следовательно, расходов инвесторов по хеджированию валютных рисков.

6.4. Организация Агентства привлечения $u$ продвижения инвестиций (АППИ) и Центра привлечения инвесторов (ЦПИ). Выше мы не раз говорили о необходимости АППИ для выполнения различных функций. Анализ мирового опыта показывает, что практически во всех странах имеются агентства продвижения инвестиций (investment promotion agency), основные функции которых описаны в разделе 3 статьи. Исходя из этого опыта, представляется целесообразными организовать АППИ в нашей стране и придать ему функции создание имиджа России, как инвестиционно привлекательной страны, продвижение имиджа российских регионов и особых территорий, пропаганда инвестиционной политики страны.

Кроме того, функциями АППИ могут стать:

- участие в создании законодательнонормативной и методической базы управления инвестиционными процессами в стране, в разработке Единой стратегии развития особых территорий, в разработке Инвестиционного кодекса, который включит в себя законы об особых территориях, поддержке, защите и поощрения ин- вестиций;

- методическое руководство региональными агентствами привлечения инвестиций, помощь в разработке стратегий инвестиционного развития регионов и отдельных особых территорий;

- стратегическое управление инвестиционными потоками (п. 6.1), включая направление инвестиций в особые территории, соответствующие их профилю.

Непосредственную работу с инвесторами, их обслуживание, а также повседневную работу с региональными администрациями, агентствами, управляющими компаниями особых территорий предлагается поручить Центру привлечения инвесторов (ЦПИ), который может быть как подразделением АППИ, так и самостоятельной организацией.

ЦПИ может вести следующие работы:

- разработка по заказу регионов инвестиционных проектов в соответствии с инвестиционными программами и национальными отраслевыми стратегиями развития с целью их продвижения в форме публичных предложений а рамках Федерального закона от 1 апреля 2020 г. № 69-Ф3 «О защите и поощрении капиталовложений в Российской Федерации»;

- консалтинговое, сервисное и юридическое обслуживание регионов при привлечении инвесторов, в том числе зарубежных;

- организация работы с инвесторами: обеспечение взаимодействия с международными базами данных инвесторов, зарубежными агентствами по привлечению инвестиций (API), фондами прямых инвестиций, клубами инвесторов и др.;

- предоставление специально оборудованных помещений для презентаций инвестиционных проектов, детального обсуждения инвестиционных предложений и условий, всей необходимой для переговоров информации, оборудования и услуг (переводчиков, консультантов и т.д.).

- консалтинговая поддержка инвесторов и представителей регионов при проведении переговоров по контрактам: подготовка инвестиционных досье, презентаций, инвестиционных питчей, видео-материалов и т.д.;

- организация маркетинговых исследований рынков инвестиционных проектов по заказам инвесторов и регионов.

Заметим, что приведенное разделение функций между АППИ и ЦПИ довольно условно, и легко может быть изменено. 


\section{Библиографический список}

1. Минэкономразвития предложило меры для роста инвестиций в РФ на $70 \% .9$ декабря 2020 года. https:// www.interfax.ru/business/740504

2. Global investment flows flat in 2019, moderate increase expected in 2020. https://unctad.org/news

3. Отчет о результатах функционирования особых экономических зон за 2019 год и за период с начала функционирования особых экономических зон. Минэкономразвития.

4. https://economy.gov.ru/material/directions/regionalnoe_razvitie/instrumenty_razvitiya_territoriy/tor/page

5. Итоговый отчет. Ассоциация индустриальных парков. 2020 год. https://indparks.ru/upload/iblock/81e/ summary\%202020\%20AIPupdo.pdf

6. Mapping of Investment Promotion Agencies in OECD countries https://indparks.ru/upload/iblock/81e/ summary\%202020\%20AIPupdo.pdf

7. State of investment promotion agencies. Evidence from WAIPA-WBG's Joint Global Survey Public. 2020.

8. Национальный проект «Малое и среднее предпринимательство и поддержка индивидуальной предпринимательской инициативы». http://government.ru/rugovclassifier/864/events/

9. Федеральный проект. Акселерация субъектов малого и среднего предпринимательства. План мероприятий. https://futurerussia.gov.ru/akseleracia-subektov-malogo-i-srednego-predprinimatelstva 